\title{
Immunomodulatory effects of OX40Ig gene-modified adipose tissue-derived mesenchymal stem cells on rat kidney transplantation
}

\author{
TAO LIU ${ }^{1 *}$, YUE ZHANG $^{2 *}$, ZHONGYANG SHEN ${ }^{3}$, XUNFENG ZOU $^{4}$, \\ XIAOBO $\mathrm{CHEN}^{5}$, $\mathrm{LI} \mathrm{CHEN}^{1}$ and YULIANG WANG ${ }^{1}$

\begin{abstract}
${ }^{1}$ Department of Clinical Laboratory Medicine, Tianjin First Central Hospital, Key Laboratory for Critical Care Medicine of the Ministry of Health, Tianjin 300192; ${ }^{2}$ Reproductive Center, Tianjin Central Hospital of Gynecology Obstetrics, Tianjin 300100; Departments of ${ }^{3}$ Transplantation Surgery and ${ }^{4}$ General Surgery, Tianjin First Central Hospital,
\end{abstract} \\ Tianjin 300192; ${ }^{5}$ Union Stem and Gene Engineering Co., Ltd., Tianjin 300384, P.R. China
}

Received November 25, 2015; Accepted November 7, 2016

DOI: $10.3892 /$ ijmm.2016.2808

\begin{abstract}
Recent studies have suggested that adipose tissuederived mesenchymal stem cell (ADSC) therapy and OX40 costimulation blockade are two immunomodulatory strategies used to suppress the immune response to alloantigens. However, relatively little has been reported regarding the immunomodulatory potential of the abilityof these two strategies to synergize. Thus, in the present study, we aimed to investigate OX40-Ig fusion protein (OX40Ig) expression in ADSCs and to validate their more potent immunosuppressive activity in preventing renal allograft rejection. For this purpose, ADSCs from Lewis rats were transfected with the recombinant plasmid, pcDNA3.1(-)OX40Ig, by nucleofection. The ADSCs transduced with the plasmid (termed ADSCs ${ }^{\text {OX40Ig }}$ ) or untransduced ADSCs (termed ADSCs ${ }^{\text {native }}$ ) were added to allostimulated mixed lymphocyte reaction (MLR) in vitro. In vivo, $\mathrm{ADSCs}^{\mathrm{OX} 40 \mathrm{Ig}}, \mathrm{ADSCs}^{\text {native }}$, or PBS were administered to an allogeneic renal transplantation model, and the therapeutic effects, as well as the underlying mechanisms were examined. The results revealed that both the ADSCs ${ }^{\text {native }}$ and ADSCs ${ }^{\text {OX40Ig }}$ significantly suppressed $\mathrm{T}$ cell proliferation and increased the percentage of $\mathrm{CD} 4{ }^{+} \mathrm{CD} 25^{+}$regulatory $\mathrm{T}$ cells in allogeneic MLR assays, with the ADSCs ${ }^{\text {OX40Ig }}$ being more effective. Furthermore, the results from our in vivo experiments revealed that compared with the ADSCs ${ }^{\text {native }}$ or PBS group, the administration of autologous ADSCs ${ }^{\text {OX40Ig }}$ markedly prolonged the mean
\end{abstract}

Correspondence to: Professor Yuliang Wang or Professor Li Chen, Department of Clinical Laboratory Medicine, Tianjin First Central Hospital, 24 Fukang Road, Nankai, Tianjin 300192, P.R. China

E-mail: wang_yu_1@163.com

E-mail: 2356677342@qq.com

${ }^{*}$ Contributed equally

Key words: adipose tissue-derived mesenchymal stem cells, OX40, fusion protein, rat renal transplantation, acute rejections survival time of renal grafts, reduced allograft rejection, and significantly downregulated the mRNA expression of intragraft interferon- $\gamma($ IFN- $\gamma)$, and upregulated the mRNA expression of interleukin (IL)-10, transforming growth factor- $\beta$ (TGF- $\beta$ ) and forkhead box protein 3 (Foxp3). The findings of our study indicate that the use of ADSCs ${ }^{\text {OX } 40 I g}$ is a promising strategy for preventing renal allograft rejection. This strategy provides the synergistic benefits of ADSC immune modulation and OX40OX40L pathway blockade, and may therefore have therapeutic potential in clinical renal transplantation.

\section{Introduction}

Organ transplantation is the most effective treatment for end-stage organ failure (1). The surgical methods of organ transplantation are now widely used; however, allograft rejection limits its further development. A major task in transplantation research is to rapidly achieve a state of immunological tolerance to alloantigens (2). T cells play a key role in regulating transplantation immunology. Allospecific T cell tolerance implies that $\mathrm{T}$ cells do not mount pathogenic immune reactions towards allogeneic organs, but preserve protective activity towards environmental pathogens. Thus, allospecific tolerized $\mathrm{T}$ cells are critical to accomplishing transplantation tolerance $(3,4)$.

Costimulation blockade is an emerging therapeutic strategy in transplantation medicine that circumvents the need for lifelong chronic immunosuppression by inhibiting the activation of the immune system at the time of transplantation (5). OX40 is a costimulatory receptor expressed primarily on activated $\mathrm{CD}^{+}$and $\mathrm{CD}^{+} \mathrm{T}$ cells. OX40 ligand (OX40L) is expressed on activated antigen-presenting cells and binds to OX40, inducing an agonistic response in $\mathrm{T}$ lymphocytes, that results in cell proliferation, increased cytokine production and the longterm survival of T lymphocytes (6). As a costimulator, OX40 is a promising drug target for $\mathrm{T}$ cell-mediated inflammatory diseases (7). The blockade of the OX40 and OX40L pathway has been shown to inhibit graft rejection and graft-versus-host disease (GVHD), and to ameliorate autoimmune diseases $(8,9)$. In addition, we previously demonstrated that the blockade of the 
OX40-OX40L pathway by OX40-Ig fusion protein (OX40Ig) may induce antigen-specific $\mathrm{T}$ cell anergy in vitro in patients with acute renal allograft rejection (10).

Cell therapies applied to solid organ transplantation have gained much attention over the past years, and among these therapies, mesenchymal stem/stromal cell (MSC) therapy has strongly emerged as one of the main therapies. In addition to their potential role in therapies for renal repair, the immunomodulatory properties of MSCs offer promise as a novel cellular therapy for the long-term protection of kidney allografts (11). Although the most common and well-characterized source of MSCs is the bone marrow, adipose tissue is the most promising source of MSCs suitable for autologous stem cell therapy. Adipose tissue has several advantages as a tissue stem cell source, including the richest source, easy accessibility, less invasive collection procedures and safe, autologous cell transplantation without immune rejection (12-14). Although MSC-based therapies have been shown to be safe and effective to a certain degree, the efficacy of MSCs in vivo remains low in most cases when MSCs are applied alone.

MSC monotherapy and costimulation blockade modulate many of the same components of the immune system and can induce the peripheral conversion of $T$ cells into regulatory $\mathrm{T}$ cells (Tregs). These two treatment strategies are being tested independently in clinical organ transplantation and in autoimmune diseases. Since these strategies share common goals and converge on some of the same target cells, it seems imperative to study their ability to synergize in downmodulating immune responses. For example, Takahashi et al (15) demonstrated that the combination of MSCs and costimulation blockade yielded superior islet graft survival and function. However, the half-time of an injected Ig fusion protein is reduced and the patient needs more of the biological agent to achieve the same effect in vivo. To enhance their therapeutic efficacy, genetic engineering is one approach to improve the in vivo performance of MSCs. As MSCs migrate to the target tissue, the therapeutic agent can be released in a local and sustained manner.

The aim of the present study was to clone OX40Ig to generate a recombinant pcDNA3.1(-)OX40Ig vector and transduce the vector into Lewis rat recipient adipose tissue-derived mesenchymal stem cells (ADSCs). We also investigated the anti-proliferative activity in vitro, as well as the prevention of graft rejection following allogeneic renal transplantation.

\section{Materials and methods}

Animals. A total of 60 age-matched inbred male Brown Norway $\left(\mathrm{BN}, \mathrm{RT}^{\mathrm{n}}\right)$ and 84 Lewis $\left(\mathrm{LEW}, \mathrm{RT}^{\mathrm{l}}\right)$ rats weighing 200 to $250 \mathrm{~g}$ were obtained from the Academy of Military Medical Science [Beijing, China; certificate no. SCXK (JUN) 2007-004]. These animals were maintained in a standard animal laboratory with free activity and free access to water and rodent chow. They were maintained in a temperature controlled environment at $22-24^{\circ} \mathrm{C}$ with a $12 \mathrm{~h}$ light/dark cycle. The rats were fasted for $12 \mathrm{~h}$ prior to surgery, and were provided with free access to $10 \%$ glucose water following surgery. All the surgical procedures were performed under sanitary conditions, and all the experiments were performed according to the National Institutes of Health Guide for Care and Use of Laboratory Animals (16). The present study was approved (approval ID no. E2013008K) by the Ethics Committee of Tianjin First Central Hospital (Tianjin, China).

Isolation and characterization of MSCs from rat adipose tissue. ADSCs were isolated from LEW rats $(n=72)$ using a previously described method (17). Briefly, the rats were anesthetized with isoflurane inhalation (LUNAN Pharmaceutical Co., Ltd., Shandong, China) 14 days before mixed lymphocyte reaction (MLR) assay and autologous cell transplantation, and the subcutaneous adipose tissue was then obtained from the hemi-inguinal regions of these rats, which were carefully excised and minced into $\sim 1 \mathrm{~mm}^{3}$ sections. The adipose tissue was digested in collagenase type I solution (Sigma-Aldrich, St. Louis, MO, USA) for $60 \mathrm{~min}$ at $37^{\circ} \mathrm{C}$ with constant agitation $(100 \mathrm{rpm})$. The stromal cells were separated from the floating adipocytes by centrifugation at $200 \mathrm{x} \mathrm{g}$ for $5 \mathrm{~min}$ at room temperature. The cells released were then resuspended in DMEM/F12 medium (Gibco, Waltham, MA, USA), then sieved through a $70 \mu \mathrm{m}$ mesh (BD Falcon, Bedford, MA, USA). The resulting ADSCs were cultivated in DMEM/F12 medium containing $10 \% \mathrm{FBS}$ (Gibco). When the cells reached confluence, the adherent cells were detached with trypsin/ethylenediaminetetraacetic acid (EDTA) (Sigma-Aldrich) and reseeded for expansion. Following in vitro culture for 14 days at $37^{\circ} \mathrm{C}$, $5 \% \mathrm{CO}_{2}$ and $95 \%$ humidity, we obtained a sufficient amount of ADSCs for autologous transplantation. The cultured ADSCs $\left(3 \times 10^{6}\right)$ from each experimental rat were respectively labeled and cryopreserved in liquid nitrogen [Air Products and Chemicals (Tianjin) Co., Ltd., Tianjin, China] prior to injection.

The cultured ADSCs were characterized for the expression of hematopoietic markers, CD34 and CD45, and mesenchymal cell markers, CD90, CD73 and CD105 by fluorescence-activated cell sorting (FACS) analysis using a flow cytometer (FACSCalibur flow cytometer; Becton-Dickinson, Franklin Lakes, NJ, USA), and data were analyzed using the CellQuest software program.

Multi-differentiation ability of ADSCs. ADSCs were also confirmed by their capacity to differentiate into adipogenic, islet and osteogenic lineages as previously described (17). Briefly, the ADSCs were seeded in medium at $2 \times 10^{4}$ cells $/ \mathrm{cm}^{2}$ in 6-well tissue culture plates. When the cells reached $100 \%$ confluency, DMEM/F12 was subsequently replaced with specific inducer medium. Adipogenic inducer medium is DMEM/F12 containing $1 \mu \mathrm{mol} / 1$ dexamethasone, $0.5 \mathrm{mmol} / 1$ 3-isobutyl-1-methylxanthine (Sigma-Aldrich), $5 \mathrm{mg} / 1$ insulin (Sigma-Aldrich), $100 \mu \mathrm{mol} / 1$ indomethacin (Sigma-Aldrich). Islet inducer medium is DMEM (high glucose; Gibco) containing $10 \mathrm{mmol} / \mathrm{l}$ nicotinamide (Sigma-Aldrich), $100 \mu \mathrm{g} / \mathrm{l}$ conophylline (BioBioPha, Yunnan, China), $10 \mu \mathrm{g} / 1$ betacellulin (PeproTech, Rocky Hill, NJ, USA), $10 \mu \mathrm{g} / 1$ hepatocyte growth factor (HGF) (PeproTech), 2\% B27 supplement (Gibco), 1\% N2 supplement (Gibco). Osteogenic inducer medium is DMEM/ F12 containing $100 \mathrm{nmol} / \mathrm{l}$ dexamethasone (Sigma-Aldrich), $10 \mathrm{mmol} / 1 \beta$-sodium glycerophosphate (Sigma-Aldrich) and $50 \mu \mathrm{g} / \mathrm{ml}$ vitamin C (Sigma-Aldrich). Following a 21-day induction period, adipocytes, islet-like cells, and osteoblasts were identified by Oil Red O staining (Sigma-Aldrich), dithizone staining (Sigma-Aldrich), and Alizarin Red S staining (Genmed, Shanghai, China), respectively. 
Eukaryotic expression vector construction. Briefly, the NCBI database was screened for coding sequences of rat OX40 extracellular domains. RNA was extracted from rat peripheral blood mononuclear cells (PBMCs) using TRIzol reagent (Life Technologies, Carlsbad, CA, USA). cDNA was synthesized using a reverse transcription system (Promega, Madison, WI, USA). The cycling conditions for polymerase chain reaction (PCR) were $94^{\circ} \mathrm{C}$ for $4 \mathrm{~min}$; followed by 32 cycles of $94^{\circ} \mathrm{C}$ for $60 \mathrm{sec}$, $58^{\circ} \mathrm{C}$ for $60 \mathrm{sec}$, and $72^{\circ} \mathrm{C}$ for $60 \mathrm{sec}$; and then $72^{\circ} \mathrm{C}$ for $10 \mathrm{~min}$. OX40 primers, designed with Primer Premier 5.0 software (Premier Biosoft, Palo Alto, CA, USA), were added into the cDNA mixture for PCR amplification (Promega). The primers used were designed as follows (forward and reverse, respectively): 5'-ACGGGATCCACCACCATGGTTACAGT GAAGCTCAAC-3' and 5'-CGGAATTCAGGGCCCTCAGG AGCCACC-3' (underlined letters denote restriction endonuclease recognition sequences). These PCR products were inserted into the pcDNA3.1(+)/linker (Life Technologies) plasmid using $B a m \mathrm{HI}$ and $E c o$ RI restriction sites to generate the recombinant plasmid, pcDNA3.1(+)/OX40-linker. The plasmid was double-checked by BamHI-EcoRI digestion with electrophoresis on agarose gel and sequencing (Sangon Biotech Co., Ltd., Shanghai, China).

A PCR-amplified cDNA fragment encoding the human $\mathrm{IgG} \mathrm{Fc}$ fragment was inserted into the $\mathrm{XhoI}$ and $\mathrm{XbaI}$ sites of the pcDNA3.1(+)/OX40-linker vector to obtain the eukaryotic expression vector (plasmids) pcDNA3.1(+)/OX40-IgG Fc (pcDNA3.1/OX40Ig). The human IgG Fc primers used were designed as follows (forward and reverse, respectively): 5'-GTCAGCTCGAGGCAAGCTTCAAGGGCC-3' and 5'-GCTCTAGACTATTTACCCGGAGACAGGGAGAG-3' (the underlined letters denote restriction endonuclease recognition sequences). The constructed plasmids were verified by double restriction endonuclease digestion and DNA sequence analysis to confirm the sequence accuracy. The cytomegalovirus (CMV) promoter pcDNA3.1(+)/GFP (Invitrogen, Carlsbad, CA, USA) was used to gauge the transfection efficiency.

ADSC nucleofection. The nucleofection of the ADSCs was performed according to the optimized protocols provided by the manufacturer (Amaxa Biosystems, Cologne, Germany). Briefly, prior to nucleofection, a Petri dish culture containing $1 \mathrm{ml}$ of DMEM was incubated in the $\mathrm{CO}_{2}$ incubator at $37^{\circ} \mathrm{C}$. The ADSCs were digested and centrifuged following the adjustment of the density of the suspended cells to $2 \times 10^{6} / \mathrm{ml}$. The cells $\left(5 \times 10^{5}\right)$ and plasmid $(2 \mu \mathrm{g})$ were suspended in $100 \mu \mathrm{l}$ prewarmed nucleofector solution (Amaxa Biosystems). For nucleofection, the program U-23 was selected. Immediately, following nucleofection, the cells were transferred into prewarmed fresh medium in six-well plates, and incubated in a $\mathrm{CO}_{2}$ incubator at $37^{\circ} \mathrm{C}$ and monitored daily. The cells were analyzed $24 \mathrm{~h}$ post-nucleofection for transfection efficiency by FACS (FACSCalibur flow cytometer; Becton-Dickinson) and a Nikon Ts100 fluorescence microscope (Nikon Corp., Tokyo, Japan) for GFP expression. The ADSCs transduced with pcDNA3.1/OX40Ig or pcDNA3.1/GFP are referred to as $\mathrm{ADSCs}^{\mathrm{OX} 40 \mathrm{Ig}}$ or $\mathrm{ADSCs}^{\mathrm{GFP}}$, respectively.

Western blot analysis. The transduced OX40Ig was confirmed by western blot analysis, as previously described (18). Briefly, the transduced ADSCs (ADSCs ${ }^{\text {OX40Ig }}$ or $\mathrm{ADSCs}^{\mathrm{GFP}}$ ) were fractionated on a $12 \%$ SDS-polyacrylamide gel, and the fractionated proteins were electrophoretically transferred onto nitrocellulose membranes (Millipore, Billerica, MA, USA). The protein samples were then incubated with primary anti-OX40 rabbit polyclonal antibodies (Cat no. ab203220) and thereafter with a horseradish peroxidase-conjugated goat anti-rabbit IgG antibody (Cat no. ab6721) (both from Abcam, Cambridge, MA, USA). Protein bands were visualized using an ECL western blotting kit (Amersham Pharmacia Biotech, Piscataway, NJ, USA).

$M L R$ assay. To test the allostimulatory activity of the genetransduced ADSCs, one-way MLR were performed. Splenocytes from the 24 BN and 24 LEW rats were filtered through nylon cell strainers (BD Falcon). The lymphocyte population was purified by density gradient centrifugation using a commercially lymphocyte separation medium (Sigma-Aldrich) and centrifuged at $400 \mathrm{x}$ g for $25 \mathrm{~min}$. The LEW lymphocytes ( $1 \times 10^{5}$, responders) and $\mathrm{BN}$ lymphocytes $\left(2 \times 10^{5}\right.$, stimulator) were co-cultured with untransduced $\mathrm{ADSCs}\left(\mathrm{ADSCs}^{\text {native }}\right), \mathrm{ADSCs}^{\mathrm{GFP}}$, or $\mathrm{ADSCs}^{\mathrm{OX} 40 \mathrm{Ig}}(1 \times 104)$ in $0.2 \mathrm{ml}$ of culture medium. The stimulator was mitotically inactivated with $50 \mu \mathrm{g} / \mathrm{ml}$ mitomycin C (SigmaAldrich) at $37^{\circ} \mathrm{C}$ for $30 \mathrm{~min}$ prior to MLR co-culture, while the responder was not treated. The mitomycin $\mathrm{C}$ pre-treated $\mathrm{ADSCs}^{\text {native }}, \mathrm{ADSCs}^{\mathrm{GFP}}$, or $\mathrm{ADSCs}^{\mathrm{OX} 40 \mathrm{Ig}}$ were allowed to adhere to the plate for $2 \mathrm{~h}$ before the lymphocytes were added to allow attachment. The cultures were maintained at $37^{\circ} \mathrm{C}$ in a humidified atmosphere of $5 \% \mathrm{CO}_{2}$. Following routine culture for 4 days, MTT colorimetry was used to measure the absorbance values at $570 \mathrm{~nm}$ in each well. The inhibitory rate was calculated according to the following formula: inhibitory rate $(\%)=(1-$ average absorbance for experimental group/ average absorbance for control group) x100.

Flow cytometric assessment of $\mathrm{CD}^{+} \mathrm{CD} 25^{+}$Tregs. The cells were analyzed for Treg markers using mouse anti-rat monoclonal antibody to CD4 (Cat no. 554843) and CD25 (Cat no. 554866) (both from BD Biosciences, San Diego, CA, USA). A FACSCalibur flow cytometer was used to determine the $\mathrm{CD} 4{ }^{+} \mathrm{CD} 25^{+}$cells, and data analysis was performed using CellQuest software (both from BD Biosciences, Franklin Lakes, NJ, USA).

Rat renal transplantation model. For orthotopic renal transplantation, the $36 \mathrm{LEW}$ rats received a kidney from the $36 \mathrm{BN}$ rats using a previously described technique (19). In brief, following humane animal sacrifice by deep anesthesia with isoflurane inhalation (LUNAN Pharmaceutical Co., Ltd.), the kidneys from the BN rats were harvested, perfused with hypertonic citrate-adenine preservation (HC-A) solution (provide by the Long March Hospital of Shanghai, China) to remove blood from the vascular beds and maintained at $4^{\circ} \mathrm{C}$ until implantation. The kidney grafts were transplanted orthotopically into left nephrectomized LEW rat recipients, and the blood flow was restored using standard microsurgical techniques. The contralateral kidneys were removed immediately following the implantation of the left kidney graft. After the effect of graft reperfusion was observed, the abdomen was closed. No immunosuppressive agents were provided. All microsurgical procedures were performed by one surgeon. Five days post-transplantation, the rats were euthanized by deep 
anesthesia as described above, the grafts were removed and subjected to morphological, reverse transcription-quantitative PCR (RT-qPCR) and biochemical analysis.

Cell transplantation procedures. In the BN-LEW allograft models, the LEW recipient rats were injected with autologous $2.0 \times 10^{6}$ ADSCs diluted in $1 \mathrm{ml}$ PBS or $1 \mathrm{ml}$ PBS alone via the penile vein 4 days prior to transplantation, and intrarenal injection performed immediately following reperfusion, followed by an intravenous injection $6 \mathrm{~h}$ after the ischemia/reperfusion (I/R) procedure through the penile vein. The LEW-LEW syngeneic transplant models $(n=12)$ were used as a control group.

The animals were randomly divided into 4 groups as follows: the isografts control group $(n=12)$, the PBS control group $(n=12)$, the $\operatorname{ADSC}^{\text {native }}$-treated group $(n=12)$, and the $\mathrm{ADSCs}^{\mathrm{OX} 40 \mathrm{Ig}}$-treated group $(\mathrm{n}=12)$.

Renal function analysis. The $2 \mathrm{ml}$ of blood was collected from the inferior vena cava at days 5 post-transplantation. Serum creatinine ( $\mathrm{SCr}$ ) levels were determined as a measure of renal function via an enzymatic colorimetric method using an automatic biochemistry analyzer (Hitachi High-Technologies Corp., Tokyo, Japan).

Renal histopathological analysis. The excised kidneys were fixed in formalin overnight and embedded in paraffin wax. Five-micrometer-thick kidney sections were deparaffinized and fixed. For histological analysis, the sections were stained with hematoxylin and eosin (H\&E; Sigma-Aldrich), and observed using a Nikon Ni-U fluorescence microscope (Nikon Corp.).

Examination of gene expression by $R T-q P C R$. Total RNA was extracted from the frozen kidney tissue samples using TRIzol reagent (Invitrogen) and then subjected to reverse transcription using a High Capacity cDNA Reverse Transcription kit (Applied Biosystems Life Technologies, Foster City, CA, USA). qPCR was performed using an ABI 7500 Sequence Detection System (Applied Biosystems Life Technologies) with SYBRGreen (Takara, Tokyo, Japan). Rat primer sequences for intragraft interferon- $\gamma($ IFN- $\gamma)$, interleukin (IL)-4, IL-10, transforming growth factor- $\beta$ (TGF- $\beta$ ), forkhead box protein 3 (Foxp3) and $\beta$-actin were as follows: IFN- $\gamma$ sense, 5 '-AGG CCATCAGCAACAACATAAGTG-3' and antisense, 5'-GAC AGCTTTGTGCTGGATCTGTG-3'; IL-4 sense, 5'-AGAAG CTGCACCGTGAATGA-3' and antisense, 5'-TCGTAGG ATGCTTTTTAGGCTTTC-3'; IL-10 sense, 5'-AAGGCCA TGAATGAGTTTGACAT-3' and antisense, 5'-CGGGTGG TTCAATTTTTCATTT-3'; TGF- $\beta$ sense, 5'-CAAGGGCTA CCATGCCAACT-3' and antisense, 5'-CCGGGTTGTGTT GGTTGTAGA-3'; Foxp3 sense, 5'-ACCGTATCTCCTGAG TTCCAT-3' and antisense, 5'-GTCCAGCTTGACCACA GTTTAT-3'; and $\beta$-actin sense, 5'-CGTTGACATCCGT AAAGACCTC-3' and antisense, 5'-TAGGAGCCAGG GCAGTAATCT-3'. The level of expression was calculated using the $2^{-\Delta \mathrm{Ct}}$ method, in which $\Delta \mathrm{Ct}$ was calculated as the $\mathrm{Ct}$ value of the target molecule - the Ct value of $\beta$-actin.

Statistical analysis. Data are expressed as the means \pm standard deviation. Comparisons among treatment groups were analyzed by one-way analysis of variance (ANOVA). Animal

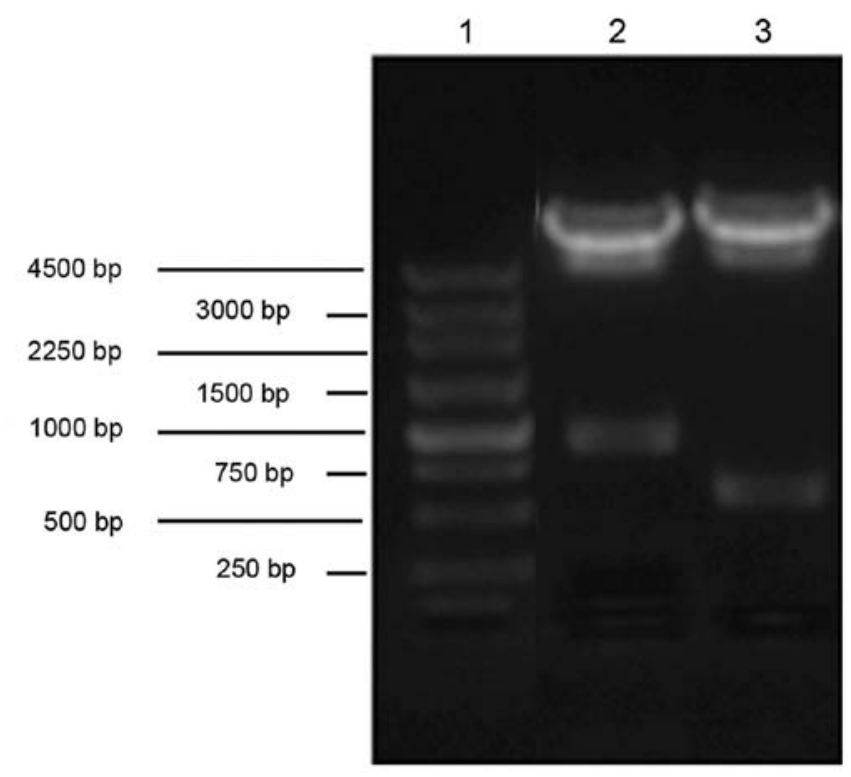

Figure 1. Validation of the recombinant plasmid pcDNA3.1/OX40Ig. Lane 1, DNA ladder; lane 2, XhoI and XbaI double digested products of the recombinant plasmid, $990 \mathrm{bp}$; lane 3, BamHI and EcoRI double digested products of the recombinant plasmid, $570 \mathrm{bp}$.

survival analysis was performed using Kaplan-Meier survival estimates, and statistical significance was analyzed by the log-rank test. Statistical analyses were performed using SPSS 16.0 software (SPSS Inc., Chicago, IL, USA). A value of $\mathrm{P}<0.05$ was considered to indicate a statistically significant difference.

\section{Results}

Recombinant eukaryotic expression plasmid. The recombinant vector, pcDNA3.1/OX40Ig, was identified by restrict enzyme digestion assay (Fig. 1). The DNA sequencing data of the pcDNA3.1/OX40Ig was consistent with DNA sequences of OX40 (extra) and IgG Fc listed in GenBank (data not shown).

Phenotypic and functional characterization of rat ADSCs. The adherent ADSCs had a spindle-shaped fibroblastic morphology following expansion. The rat ADSCs expressed typical markers and differentiation profiles. They strongly expressed the stem cell markers, CD90, CD73 and CD105, but were negative for the hematopoietic markers, CD34 and CD45, as shown by flow cytometric analysis (Fig. 2A). In addition, the culture-expanded ADSCs were also functionally capable of differentiating into adipocytes, islet-like cells and osteoblasts under inductive culture conditions, and this was confirmed using Oil Red O, dithizone and Alizarin Red S staining (Fig. 2B).

Analysis of nucleofection. To confirm the nucleofection efficiency, the vector pcDNA3.1/green fluorescent protein (GFP) encoding for GFP was used and observed with fluorescence microscopy and flow cytometry. Green fluorescent ADSCs ${ }^{\text {GFP }}$ could be observed (Fig. 3A and B). The expression of OX40Ig in the ADSCs was examined at the protein level. At $48 \mathrm{~h}$ posttransduction, OX40Ig protein was specifically detected in the $\mathrm{ADSCs}^{\text {OX40Ig }}$, but not in the ADSCs ${ }^{\mathrm{GFP}}$ and $\mathrm{ADSCs}^{\text {native }}$ (Fig. 3C). 

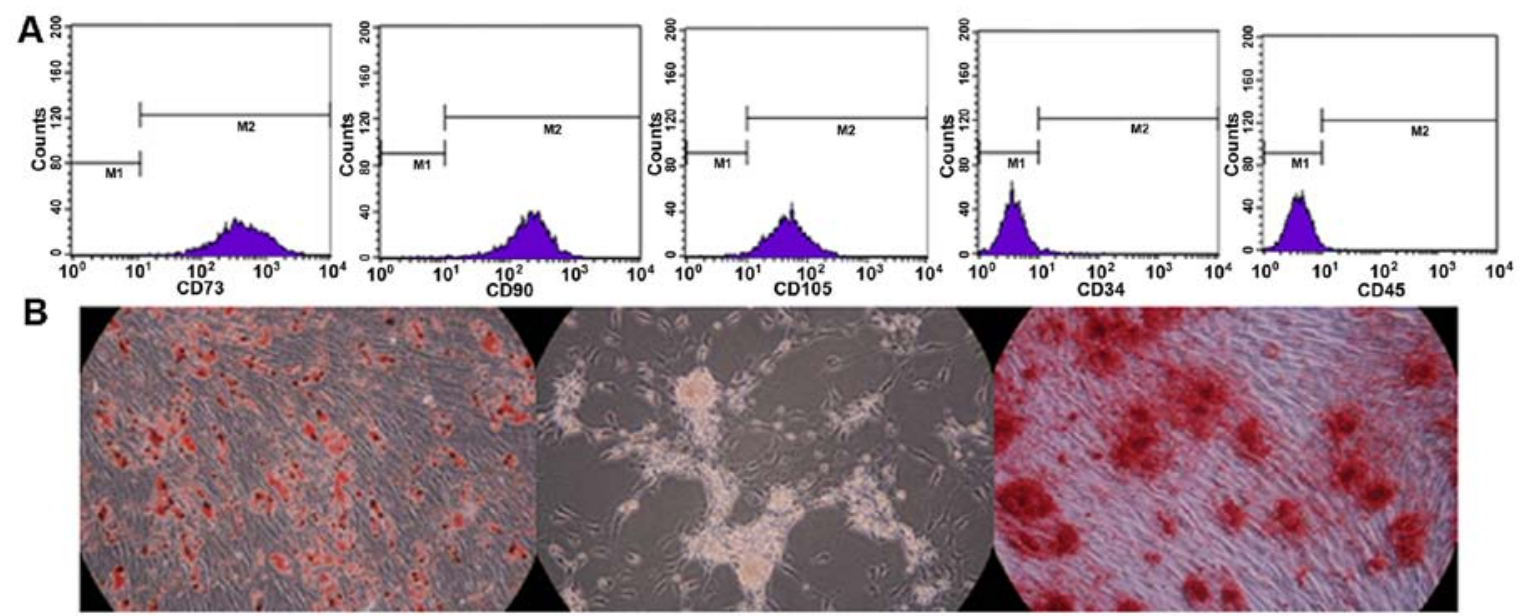

Figure 2. Characterization of adipose tissue-derived mesenchymal stem cells (ADSCs). (A) Flow cytometric characterization of ADSCs. ADSCs strongly expressed CD73, CD90 and CD105, and did not express CD34 and CD45. (B) Cells were induced to differentiate into adipocytes (left panel), islet-like cells (middle panel), or osteoblasts (right panel) (magnification, x200).

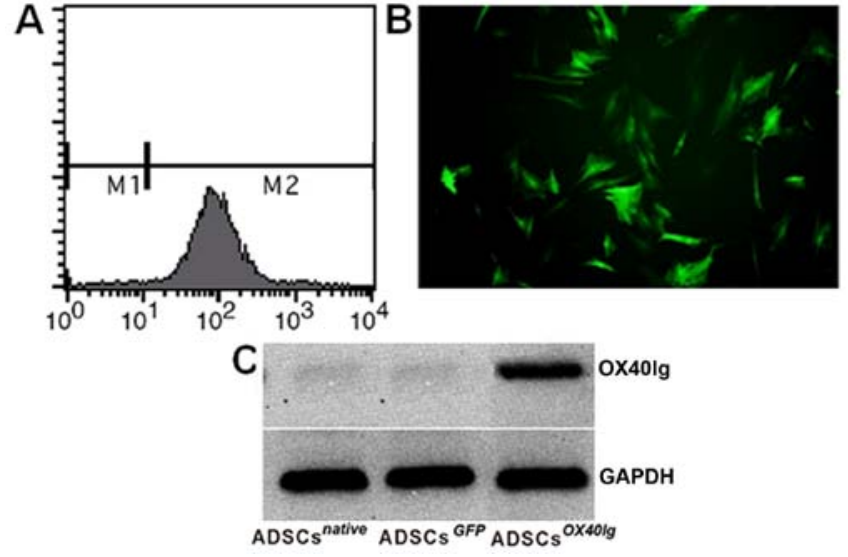

Figure 3. Nucleofection efficiency of adipose tissue-derived mesenchymal stem cells (ADSCs). (A) A flow cytometry histogram showing the level of green fluorescent protein (GFP) expression of ADSCs transfected with pcDNA3.1/GFP. (B) Staining for fluorescence microscopy showed that mesenchymal stem/stromal cells (MSCs) expressed GFP (magnification, $\mathrm{x} 400$ ). (C) Expression of OX40Ig detected by western blot analysis.

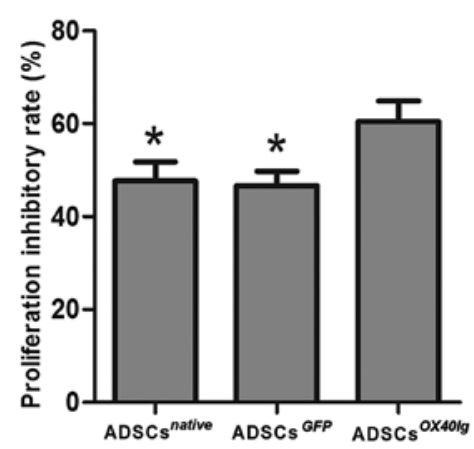

Figure 4. Proliferation inhibitory rate of allostimulated T cells by mixed lymphocyte reaction (MLR) in vitro. Data are expressed as the means \pm standard deviation. ${ }^{*} \mathrm{P}<0.01$ vs. ADSCs ${ }^{\text {OX40Ig }}$

ADSCs ${ }^{\text {OX40Ig }}$ suppresses the proliferation of allostimulated $T$ cells and modulated $T$ cell subsets in vitro. The data indicated

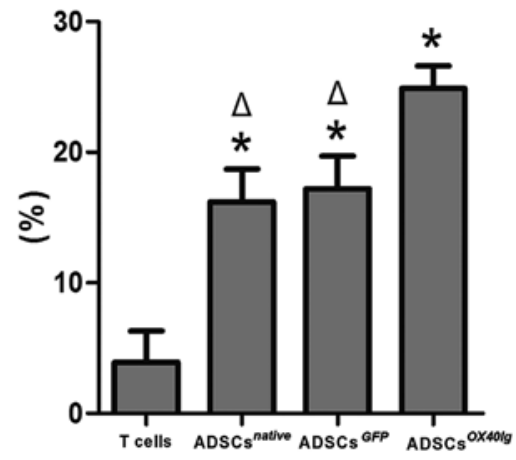

Figure 5 . Induction of $\mathrm{CD} 4^{+} \mathrm{CD} 25^{+}$regulatory $\mathrm{T}$ cells by mixed lymphocyte reaction (MLR) in vitro. Data are expressed as the means \pm standard deviation. ${ }^{*} \mathrm{P}<0.01$ vs. $\mathrm{T}$ cells and ${ }^{\triangle} \mathrm{P}<0.01$ vs. ADSCs ${ }^{\text {OX40Ig. }}$.

that the ADSCs ${ }^{\text {OX40Ig }}$ group markedly inhibited the allostimulatory $\mathrm{T}$ cell proliferation compared with the ADSCs ${ }^{\mathrm{GFP}}$ and ADSCs ${ }^{\text {native }}$ groups $(\mathrm{P}<0.01)($ Fig. 4). Flow cytometric analysis of $\mathrm{CD} 4{ }^{+} \mathrm{CD} 25^{+}$Tregs revealed that this population was significantly increased in the ADSCs ${ }^{\text {native }}$, ADSCs ${ }^{\text {GFP }}$ and $\mathrm{ADSCs}^{\text {OX40Ig }}$ groups as compared with allogeneic $\mathrm{T}$ cells cultured alone $(\mathrm{P}<0.01)$. The percentage of $\mathrm{CD}^{+} \mathrm{CD} 25^{+}$Tregs significantly increased in the ADSCs ${ }^{\text {OX40Ig }}$ group as compared with ADSCs ${ }^{\text {native }}$ and ADSCs ${ }^{\text {GFP }}$ groups $(\mathrm{P}<0.01)($ Fig. 5). These results indicate that OX40Ig genetic modification may substantially enhance the immunosuppressive ability of ADSCs to allogeneic $\mathrm{T}$ cell proliferation and may increase the number of Tregs.

Administration of ADSCs ${ }^{\text {OX40Ig }}$ ameliorates transplanted renal failure and slightly prolongs graft survival. Renal transplantation induced a substantial increase in the SCr levels in the PBS control group than in the isografts control group $(\mathrm{P}<0.01)$. The administration of $\mathrm{ADSCs}^{\text {OX40Ig }}$ and $\mathrm{ADSCs}^{\text {native }}$ significantly attenuated the increase in the SCr levels compared with the PBS control group $(\mathrm{P}<0.01)$. However, the ADSCs ${ }^{\text {OX40Ig }}$ treated group had significantly lower $\mathrm{SCr}$ levels compared with the $\mathrm{ADSCs}^{\text {native }}$ treated group $(\mathrm{P}<0.05)($ Fig. 6). Our results indicated that the isograft survival was $>90$ days. The survival of 


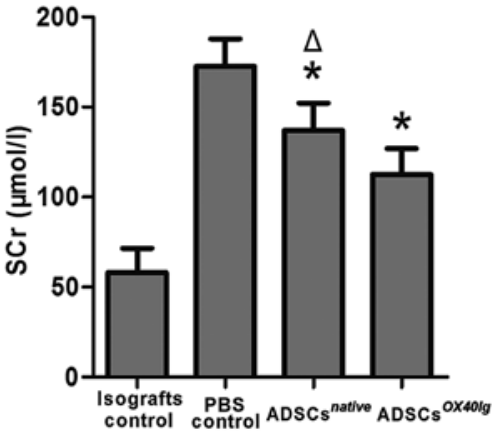

Figure 6. Improved effects of adipose tissue-derived mesenchymal stem cells (ADSCs) on renal function in allogeneic kidney transplanted animals. Renal function was assessed by measuring serum creatinine ( $\mathrm{SCr}$ ) levels. Data are expressed as the means \pm standard deviation. ${ }^{~} \mathrm{P}<0.01$ vs. PBS control and ${ }^{\Delta} \mathrm{P}<0.05$ vs. $\mathrm{ADSCs}{ }^{\mathrm{OX} 40 \mathrm{Ig}}$.

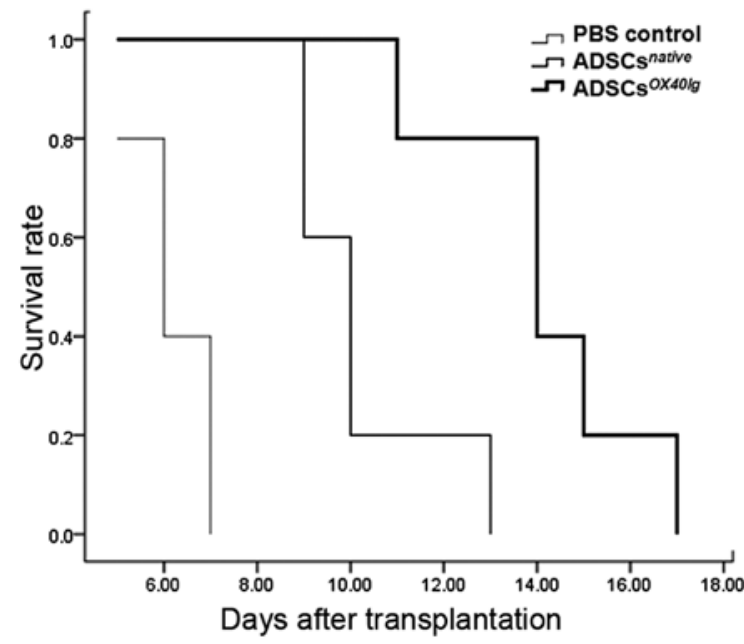

Figure 7. Kaplan-Meier curves for survival times in the rat kidney transplantation model.

the allografts in the ADSCs ${ }^{\text {native }}$ treated group $(10.2 \pm 1.6$ days $)$ was slightly, but significantly prolonged compared to that of the PBS control group $(6.2 \pm 0.8$ days) $(\mathrm{P}<0.05)$. The administration of ADSCs ${ }^{\text {OX } 401 \mathrm{~g}}$ markeldy improved allograft survival, increasing the mean graft survival time to $14.2 \pm 2.2$ days. The survival time of all recipients is shown in Fig. 7.

Renal histopathological evaluation. To determine the reason for graft failure, we then evaluated renal morphologies. The allogeneic PBS control group exhibited the histological characteristics of acute rejection, as shown by dense parenchymal mononuclear cell infiltration, extensive tubulitis and interstitial edema. By contrast, these changes were significantly attenuated (the signs of acute rejection) in the kidneys from the $\mathrm{ADSC}^{\text {native }}$ - and ADSCs $\mathrm{s}^{\mathrm{OX} 40 \mathrm{Ig}}$-treated groups, although mild interstitial edema and a small amount of inflammatory cell infiltration was observed, and some tubular dilatation, or some epithelial swelling and degeneration were present. The kidneys from the isografts control group lacked the histological signs of rejection. Consistent with the functional analysis data, the histological examination also confirmed the beneficial effects of the administration of ADSCs ${ }^{\text {OX40Ig }}$. Representative light microscopic findings are shown in Fig. 8.
Production of cytokines related to rejection or tolerance in allografts. Cytokines are key mediators in the induction and effector phases of the immune and inflammatory responses in kidney transplantation. In order to detect the effects of ADSCs on the level of rejection or tolerance-associated cytokines in allograft kidneys, we prepared total allograft mRNA for the measurement of cytokine transcript expression by RT-qPCR. Compared with the isografts control group, the allogeneic PBS control group exhibited a significantly increased mRNA expression of IFN- $\gamma$, IL- 4 , IL-10, TGF- $\beta$ and Foxp3 in the allografts. Compared with the allogeneic PBS control group, the ADSCs ${ }^{\text {native }}$ - and ADSCs $^{\text {OX40Ig }}$-treated groups exhibited a significantly decreased expression of IFN $-\gamma$ in the allografts, and there was a marked downregulation in the IFN- $\gamma$ mRNA

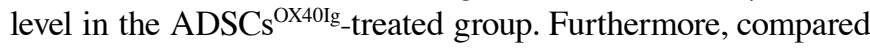
with the allogeneic PBS control group, the mRNA expression levels of IL-10, TGF- $\beta$ and Foxp3 were significantly increased

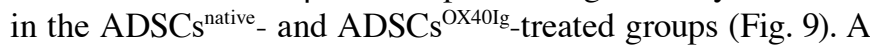
significantly higher mRNA level of the Treg marker, Foxp3, was observed in the ADSCs ${ }^{\text {OX40Ig }}$-treated group compared with the $\mathrm{ADSCs}^{\text {native-}}$-treated group (Fig. 9).

\section{Discussion}

The main approach designed to reduce graft rejection has been focused on the development of immunosuppressive agents at present. In the present study, we investigated the potential benefits of treatment with ADSCs and OX40Ig-expressing ADSCs on the modulation of the rejection response in an acute rat renal transplantation model. Our results indicated that combination of autologous ADSCs infusion and OX40-OX40L costimulation blockade may be an intriguing strategy with which to exert a synergistic immunosuppressive effect and thereby lead to the attenuation of histological damage caused by acute rejection.

The ease of isolation, the absence of costimulatory receptors, and their immunomodulatory and anti-inflammatory properties of MSCs have led to the profound idea of developing genetically engineered MSCs expressing the desired therapeutic factors as a cell based vector system $(20,21)$. MSCs can be readily transduced with all the known viral and non-viral vectors and can effectively overexpress the transgene $(22,23)$. However, the cytogenetic stability of MSCs following viral transduction needs to be established to the allay safety issues of malignant transformation. The nucleofection technology is a safe nonviral electroporation-based transfection system $(24,25)$. In this study, we modified ADSCs with the plasmid pcDNA3.1 that can expressed the OX40Ig fusion protein in eukaryotic expressiion systems by nucleofection. The transient expression of OX40Ig in ADSCs was obtained. It was proven that the OX40Ig fusion protein was expressed in ADSCs, and both of the ADSCs ${ }^{\text {native }}$ and ADSCs ${ }^{\text {OX40Ig }}$ significantly suppressed T cell proliferation, and increased the proportion of $\mathrm{CD} 4{ }^{+} \mathrm{CD} 25^{+}$ Tregs in allogeneic MLR assays in vitro, with the ADSCs ${ }^{\text {OX40Ig }}$ being more effective. This indicated that the ADSCs ${ }^{\text {OX } 4019}$ expressed OX40Ig and had biological function, and exerted synergistic effects on ADSC-mediated antigen-specific T cell anergy through blockade OX40/OX40L costimulation signals.

MSCs as a cell therapy have demonstrated efficacy for GVHD, systemic lupus erythematosus (SLE), rheumatoid arthritis (RA), multiple sclerosis (MS), type 1 diabetes, 

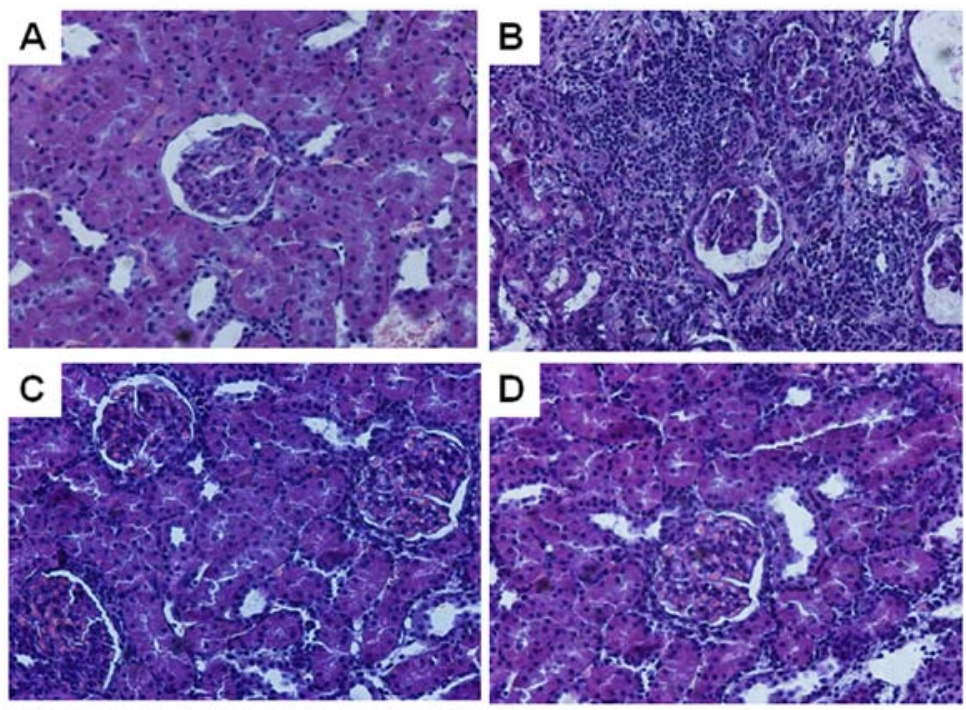

Figure 8. The histopathology of kidney allografts collected 5 days post-transplantation. Representative photomicrographs are shown (magnification, x200). (A) The isografts control group, (B) the PBS control group, (C) the adipose tissue-derived mesenchymal stem cells (ADSCs) ${ }^{\text {native }}$ treated group and (D) the $\mathrm{ADSCs}^{\mathrm{OX} 40 \mathrm{Ig}}$ treated group.

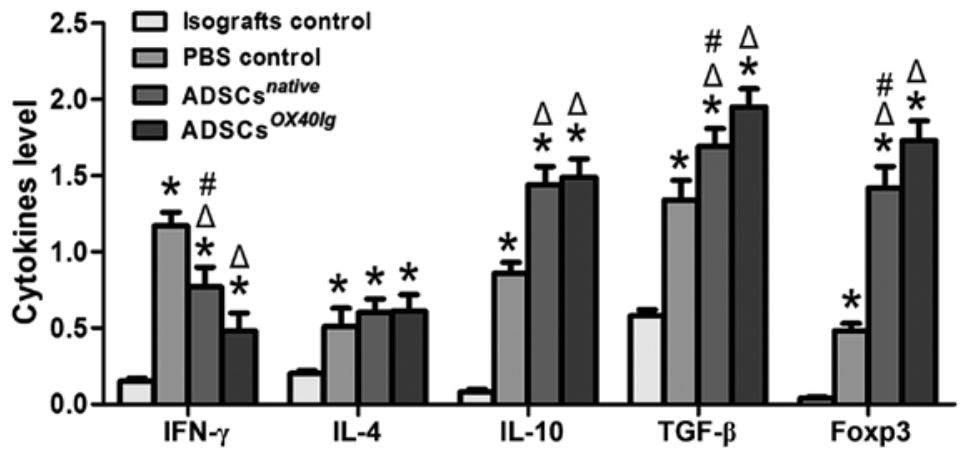

Figure 9. The levels of rejection/tolerance associated with cytokines in the grafts of recipients. Data are expressed as the means \pm standard deviation. ${ }^{*} \mathrm{P}<0.01$ vs. isografts control, ${ }^{\Delta} \mathrm{P}<0.01$ vs. $\mathrm{PBS}$ control and ${ }^{\#} \mathrm{P}<0.01$ vs. adipose tissue-derived mesenchymal stem cells (ADSCs) ${ }^{\text {OX401g. }}$

myocardial infarction, thyroditis, different types of neurological disorders and organ transplantation (26-32). ADSCs were used in clinical trials as soon as 5 years after their description $(14,33)$ and more than 100 clinical trials have been reported at http://www.clinicaltrials.gov. The first clinical study in kidney transplantation with autologous MSC treatment was reported by Perico et al (34) as a safety and feasibility study, but with limited success. Other very limited studies set up clinical trials using autologous or even allogeneic MSCs in kidney transplantation $(35,36)$. Tan et al $(37)$ demonstrated that the use of autologous MSCs as a replacement for induction therapy resulted in a lower incidence of acute rejection, decreased risk of opportunistic infection, and better estimated renal function at 1 year in living related kindey transplantation. In a rat organ transplant model, Casiraghi et al (38) observed that, in contrast to post-transplant MSC infusion, pre-transplant MSC infusion induced a significant prolongation of kidney graft survival by a Treg-dependent mechanism. Contrary data have also been published for the rat heart transplantation model, with either accelerated rejection (39) or prolonged graft survival (40) obtained depending on the experimental approach. Therefore, the time point of injection and the number of cells applied seem to be important parameters influencing the success of MSC therapy. Our observations that pre-transplant, intro-transplant, and post-transplant ADSC administration significantly improved renal function compared with the PBS control group. This result is in agreement with our previous study that autologous ADSC ameliorated acute renal damage undergoing cold $\mathrm{I} / \mathrm{R}$ injury and improved renal function (17).

However, the single administration of ADSCs is only practical for a limited number of applications, and is insufficient to overcome the alloreactive $\mathrm{T}$ cell response totally and to achieve a long-term positive allograft outcome (41). Thus, as gene delivery vehicles, the localization of ADSCs combined with costimulation blockade may provide a new opportunity for successful therapy $(15,42)$. In this study, our results revealed that the administration of OX40Ig gene-modified ADSCs resulted in a modest, but greater prolongation in the survival time of renal grafts compared with ADSC monotherapy. Furthermore, renal function and histological examination revealed that $\mathrm{ADSCs}^{\text {OX40Ig }}$ therapy significantly improved renal function and lessened tissue damage. The present results also indicated that $\mathrm{ADSCs}^{\text {OX40Ig }}$ therapy 
effectively prevented $\mathrm{T}$ lymphocyte infiltration to the grafts. This indicated that acute rejection was effectively prevented by the intrarenal ADSC immunomodulatory effect in combination with simultaneous local OX40-OX40L pathway blockade, which may contribute to a tolerogenic environment.

Infiltrated T cells produce effector cytokines in situ to recruit additional immune cells that mediate early graft tissue damage. Blocking the expression of pro-inflammatory cytokines is a rational approach to the immunosuppressive therapy of graft rejection. Cytokine transcription profiles of intragraft tissues give us a more precise insight of the immune regulation. In this study, one mechanism by with $\mathrm{ADSCs}^{\text {Ox40Ig }}$ led to the suppression of immunity and prolongation of survival involved the induction of Tregs. Consistent with previous data $(41,43)$, our study demonstrated that the gene expression profiles in grafts from the PBS group exhibited an increased expression of genes associated with Th1 cells (IFN- $\gamma$ ), Th 2 cells (IL-4 and IL-10), Th3 cells (TGF- $\beta$ ) and Tregs (Foxp3). The present study demonstrated that graft survival in the ADSCs ${ }^{\text {OX } 40 I g}$ group was enhanced, along with the significantly decreased mRNA expression of IFN- $\gamma$, and the increased mRNA expression of IL-10, TGF- $\beta$ and Foxp3. The upregulation of IL-10 and TGF- $\beta$ is important for the differentiation and proliferation of Tregs. Tregs have very important immunoregulatory effects and play a significant role in the induction of immunotolerance or the maintenance of immunosuppressive activity (44). These data provide evidence that increased allograft survival following ADSCs ${ }^{\text {OX40Ig }}$ administration, at least in part, occurs in association with the increased intragraft expression of genes associated with altered $\mathrm{T}$ cell differentiation, as well as a shift from a pro-inflammatory to an anti-inflammatory state. Further studies are warranted in order to elucidate the signal transduction pathways through which ADSCs ${ }^{\text {OX40Ig }}$ modulate $\mathrm{T}$ cells and prolong allotransplant survival.

Taken together, the results of the present study demonstrated that the administration of ADSCs ${ }^{\text {OX40Ig }}$ was able to alleviate acute renal allograft rejection and prolong graft survival by combining the immunomodulatory effects of ADSCs and ADSCs-mediated intrarenal OX40/OX40L pathway blockade. More functional assessments are still required if tolerogenic strategy utilizing ADSCs ${ }^{\text {OX40Ig }}$ is to be developed in the near future.

\section{Acknowledgements}

This study was supported by the National Natural Science Foundation of China (grant no. 81470982); the National Clinical Key Specialty Project Foundation of the Ministry of Health (grant no. 2013544); and the Tianjin Research Program of Application Foundation and Advanced Technology (grant nos. 13JCYBJC23000 and 12ZCZDSY02600).

\section{References}

1. Shrestha B, Haylor $\mathbf{J}$ and Raftery A: Historical perspectives in kidney transplantation: an updated review. Prog Transplant 25: 64-69, 76, 2015

2. Newell KA: Clinical transplantation tolerance. Semin Immunopathol 33: 91-104, 2011.

3. Thorp EB, Stehlik C and Ansari MJ: T-cell exhaustion in allograft rejection and tolerance. Curr Opin Organ Transplant 20: 37-42, 2015.
4. Waldmann H, Hilbrands R, Howie D and Cobbold S: Harnessing $\mathrm{FOXP}^{+}$regulatory $\mathrm{T}$ cells for transplantation tolerance. $\mathrm{J}$ Clin Invest 124: 1439-1445, 2014.

5. Kinnear G, Jones ND and Wood KJ: Costimulation blockade: current perspectives and implications for therapy. Transplantation 95: 527-535, 2013.

6. Kaur D and Brightling C: OX40/OX40 ligand interactions in T-cell regulation and asthma. Chest 141: 494-499, 2012

7. Jensen SM, Maston LD, Gough MJ, Ruby CE, Redmond WL, Crittenden M, Li Y, Puri S, Poehlein CH, Morris N, et al: Signaling through OX40 enhances antitumor immunity. Semin Oncol 37: 524-532, 2010.

8. Kotani A, Hori T, Fujita T, Kambe N, Matsumura Y, Ishikawa T, Miyachi Y, Nagai K, Tanaka Y and Uchiyama T: Involvement of OX40 ligand ${ }^{+}$mast cells in chronic GVHD after allogeneic hematopoietic stem cell transplantation. Bone Marrow Transplant 39: 373-375, 2007.

9. Zhou YB, Ye RG, Li YJ and Xie CM: Targeting the CD134 CD134L interaction using anti-CD134 and/or rhCD134 fusion protein as a possible strategy to prevent lupus nephritis. Rheumatol Int 29: 417-425, 2009.

10. Wang YL, Li G, Fu YX, Wang H and Shen ZY: Blockade of OX40/OX40 ligand to decrease cytokine messenger RNA expression in acute renal allograft rejection in vitro. Transplant Proc 45: 2565-2568, 2013

11. Casiraghi F, Remuzzi G and Perico N: Mesenchymal stromal cells to promote kidney transplantation tolerance. Curr Opin Organ Transplant 19: 47-53, 2014.

12. Marx C, Silveira MD and Beyer Nardi N: Adipose-derived stem cells in veterinary medicine: characterization and therapeutic applications. Stem Cells Dev 24: 803-813, 2015.

13. Alipour F, Parham A, Kazemi Mehrjerdi H and Dehghani H: Equine adipose-derived mesenchymal stem cells: phenotype and growth characteristics, gene expression profile and differentiation potentials. Cell J 16: 456-465, 2015.

14. Minteer DM, Marra KG and Rubin JP: Adipose stem cells: biology, safety, regulation, and regenerative potential. Clin Plast Surg 42: 169-179, 2015.

15. Takahashi T, Tibell A, Ljung K, Saito Y, Gronlund A, Osterholm C, Holgersson J, Lundgren T, Ericzon BG, Corbascio M and Kumagai-Braesch M, et al: Multipotent mesenchymal stromal cells synergize with costimulation blockade in the inhibition of immune responses and the induction of Foxp $3^{+}$regulatory T cells Stem Cells Transl Med 3: 1484-1494, 2014.

16. Clark JD, Gebhart GF, Gonder JC, Keeling ME and Kohn DF: Special Report: the 1996 guide for the care and use of laboratory animals. ILAR J 38: 41-48, 1997.

17. Wang YL, Li G, Zou XF, Chen XB, Liu T and Shen ZY: Effect of autologous adipose-derived stem cells in renal cold ischemia and reperfusion injury. Transplant Proc 45: 3198-3202, 2013.

18. Redmond WL, Triplett T, Floyd K and Weinberg AD: Dual anti-OX40/IL-2 therapy augments tumor immunotherapy via IL-2R-mediated regulation of OX40 expression. PLoS One 7: e34467, 2012

19. Seifert M, Stolk M, Polenz D and Volk HD: Detrimental effects of rat mesenchymal stromal cell pre-treatment in a model of acute kidney rejection. Front Immunol 3: 202, 2012.

20. Wu H, Ye Z and Mahato RI: Genetically modified mesenchymal stem cells for improved islet transplantation. Mol Pharm 8: 1458-1470, 2011.

21. Li J, Ezzelarab MB, Ayares D and Cooper DK: The potential role of genetically-modified pig mesenchymal stromal cells in xenotransplantation. Stem Cell Rev 10: 79-85, 2014.

22. Stiehler M, Duch M, Mygind T, Li H, Ulrich-Vinther M, Modin C, Baatrup A, Lind M, Pedersen FS and Bünger CE: Optimizing viral and non-viral gene transfer methods for genetic modification of porcine mesenchymal stem cells. Adv Exp Med Biol 585: 31-48, 2006.

23. Fülbier A, Schnabel R, Michael S, Vogt PM, Strauß S, Reimers K and Radtke C: Successful nucleofection of rat adipose-derived stroma cells with ambystoma mexicanum epidermal lipoxygenase (AmbLOXe). Stem Cell Res Ther 5: 113, 2014.

24. Fakiruddin KS, Baharuddin P, Lim MN, Fakharuzi NA, Yusof NA and Zakaria Z: Nucleofection optimization and in vitro antitumourigenic effect of TRAIL-expressing human adipose-derived mesenchymal stromal cells. Cancer Cell Int 14: 122, 2014.

25. Copland IB, Qayed M, Garcia MA, Galipeau J and Waller EK: Bone marrow mesenchymal stromal cells from patients with acute and chronic graft-versus-host disease deploy normal phenotype, differentiation plasticity, and immune-suppressive activity. Biol Blood Marrow Transplant 21: 934-940, 2015. 
26. Wang Q, Qian S, Li J, Che N, Gu L, Wang Q, Liu Y and Mei H: Combined transplantation of autologous hematopoietic stem cells and allogenic mesenchymal stem cells increases T regulatory cells in systemic lupus erythematosus with refractory lupus nephritis and leukopenia. Lupus 24: 1221-1226, 2015.

27. De Bari C: Are mesenchymal stem cells in rheumatoid arthritis the good or bad guys? Arthritis Res Ther 17: 113, 2015.

28. Xiao J, Yang R, Biswas S, Qin X, Zhang $M$ and Deng W: Mesenchymal stem cells and induced pluripotent stem cells as therapies for multiple sclerosis. Int J Mol Sci 16: 9283-9302, 2015

29. Kong D, Zhuang X, Wang D, Qu H, Jiang Y, Li X, Wu W, Xiao J Liu X, Liu J, et al: Umbilical cord mesenchymal stem cell transfusion ameliorated hyperglycemia in patients with type 2 diabetes mellitus. Clin Lab 60: 1969-1976, 2014.

30. Chullikana A, Majumdar AS, Gottipamula S, Krishnamurthy S Kumar AS, Prakash VS and Gupta PK: Randomized, double-blind, phase I/II study of intravenous allogeneic mesenchymal stromal cells in acute myocardial infarction. Cytotherapy 17: 250-261,2015.

31. Suksuphew S and Noisa P: Neural stem cells could serve as a therapeutic material for age-related neurodegenerative diseases. World J Stem Cells 7: 502-511, 2015.

32. Lim MH, Ong WK and Sugii S: The current landscape of adipose-derived stem cells in clinical applications. Expert Rev Mol Med 16: e8, 2014

33. Perico N, Casiraghi F, Introna M, Gotti E, Todeschini M, Cavinato RA, Capelli C, Rambaldi A, Cassis P, Rizzo P, et al: Autologous mesenchymal stromal cells and kidney transplantation: a pilot study of safety and clinical feasibility. Clin J Am Soc Nephrol 6: 412-422, 2011.

34. Perico N, Casiraghi F, Gotti E, Introna M, Todeschini M, Cavinato RA, Capelli C, Rambaldi A, Cassis P, Rizzo P, et al: Mesenchymal stromal cells and kidney transplantation: pretransplant infusion protects from graft dysfunction while fostering immunoregulation. Transpl Int 26: 867-878, 2013.

35. Peng Y, Ke M, Xu L, Liu L, Chen X, Xia W, Li X, Chen Z, Ma J, Liao D, et al: Donor-derived mesenchymal stem cells combined with low-dose tacrolimus prevent acute rejection after renal transplantation: a clinical pilot study. Transplantation 95: 161-168, 2013.

36. Reinders ME, de Fijter JW, Roelofs H, Bajema IM, de Vries DK, Schaapherder AF, Claas FH, van Miert PP, Roelen DL, van Kooten C, et al: Autologous bone marrow-derived mesenchymal stromal cells for the treatment of allograft rejection after renal transplantation: results of a phase I study. Stem Cells Transl Med 2: 107-111, 2013
37. Tan J, Wu W, Xu X, Liao L, Zheng F, Messinger S, Sun X, Chen J, Yang S, Cai J, et al: Induction therapy with autologous mesenchymal stem cells in living-related kidney transplants: a randomized controlled trial. JAMA 307: 1169-1177, 2012.

38. Casiraghi F, Azzollini N, Todeschini M, Cavinato RA, Cassis P, Solini S, Rota C, Morigi M, Introna M, Maranta R, et al: Localization of mesenchymal stromal cells dictates their immune or proinflammatory effects in kidney transplantation. Am J Transplant 12: 2373-2383, 2012.

39. Inoue S, Popp FC, Koehl GE, Piso P, Schlitt HJ, Geissler EK and Dahlke MH: Immunomodulatory effects of mesenchymal stem cells in a rat organ transplant model. Transplantation 81: 1589-1595, 2006.

40. Popp FC, Eggenhofer E, Renner P, Slowik P, Lang SA, Kaspar H, Geissler EK, Piso P, Schlitt HJ and Dahlke MH: Mesenchymal stem cells can induce long-term acceptance of solid organ allografts in synergy with low-dose mycophenolate. Transpl Immunol 20: 55-60, 2008.

41. Kato T, Okumi M, Tanemura M, Yazawa K, Kakuta Y, Yamanaka K, Tsutahara K, Doki Y, Mori M, Takahara S and Nonomura N: Adipose tissue-derived stem cells suppress acute cellular rejection by TSG-6 and CD44 interaction in rat kidney transplantation. Transplantation 98: 277-284, 2014.

42. Yang D, Wang LP, Zhou H, Cheng H, Bao XC, Xu S, Zhang WP and Wang JM: Inducible costimulator gene-transduced bone marrow-derived mesenchymal stem cells attenuate the severity of acute graft-versus-host disease in mouse models. Cell Transplant 24: 1717-31, 2015.

43. Wang YL, Tang ZQ, Gao W, Jiang Y, Zhang XH and Peng L: Influence of Th1, Th2, and Th3 cytokines during the early phase after liver transplantation. Transplant Proc 35: 3024-3025, 2003.

44. Lee JH, Jeon EJ, Kim N, Nam YS, Im KI, Lim JY, Kim EJ, Cho ML, Han KT and Cho SG: The synergistic immunoregulatory effects of culture-expanded mesenchymal stromal cells and CD4(+)25(+)Foxp3+ regulatory T cells on skin allograft rejection. PLoS One 8: e70968, 2013. 